\title{
The Study of Non-verbal Allusion Translation in Film Subtitle: Based on Relevance Theory
}

\author{
Juan Liu \\ Foreign Languages Department, Inner Mongolia University of Finance and Economics, Hohhot, China
}

Huijuan Jia

Haikou Enbo English Training School, China

\begin{abstract}
This dissertation attempts to find a proper way of translating non-verbal allusion in a film based on Relevance Theory through the comparison of two Chinese versions of The Simpsons Movie. According to Relevance Theory, the key of translation is to search and achieve the Optimal Relevance, thus non-verbal allusion subtitle translation is considered as a process of achieving Optimal Relevance between the allusions in subtitles and the Target Language Viewers.
\end{abstract}

Index Terms-Relevance Theory, Optimal Relevance, non-verbal allusion

\section{RESEARCH BACKGROUND}

Nowadays, Subtitle translation is considered to be very important while people are enjoying a foreign film, because the inaccuracy of the translation could easily misguide the understanding of the target viewers. The Subtitle language is the carrier of culture. Many examples show that one cannot learn English well if one is ignorant of the culture of the English-speaking countries. In English, there are so many heavily culture-loaded verbal and non-verbal which are easy to lead to cross-cultural failures in communication. Most of the movies are rich in allusions which are originated from various fields, including mythology, historical events, fables, religion and literary works. Allusions are of great importance in understanding the foreign culture since they have close connection with people's life. Thus, more attention should be paid to the translation of allusion subtitling to make people better understand and enjoy the original intended meaning of the movie.

The quality of subtitle translation of a film, including the translation of allusion subtitle, could have a great influence on people's understanding and appreciation of the film. It is the translator's duty to show the target language viewers the original meaning concerning cultural factors of the movie. How to understand these cultural elements and reduce differences caused by them are two problems the translator should deal with. However, just as Yves Gambier and Henrik Gottlieb point out (2001), research in subtitling is still difficult for lack of theoretical frames and methodological tools (Yves Gambier and Henrik Gottlieb, 2001). Many theories have been applied in fields of translation; however, very few researches have been done in allusion subtitle translation, especially guided by Relevance Theory.

Good translation of subtitles could help the target viewers get a proper understanding of the original and bring enjoyment to the viewers. Good translation techniques guided by proper theory could make it much easier for the target viewers to understand the film just as the original viewers do. Thus, the dissertation attempts to find a proper way of translating Non-Verbal Allusions in a film based on RT through the comparison of two Chinese versions of The Simpsons Movie.

\section{RESEARCH METHODOLOGY}

A qualitative study is adopted in the research of the allusion subtitle translation in the English movie The Simpsons Movie in order to analyze which version of Chinese translation has used better translation techniques and whether it has achieved the optimal relevance, that is, whether the two Chinese versions have the original intention clearly conveyed to the Target Language Viewers. Transcription, descriptive and comparative analysis, and exemplification are applied in this dissertation.

Transcription serves in the collection of the two versions. The version from YDY is transcribed from Internet (Net.2). The version from YYed is from the DVD released by The TWENTIETH CENTURY FOX.

Descriptive analyses are made in the case study to establish the translation brief and to analyze the source-texts. It shows how the translator conveys the original information of a film in order to make the target viewers achieve an expected understanding of the original film.

Comparative analyses are applied in target-text analysis and exemplification is used to support the viewpoints in the descriptive and comparative analyses.

\section{RESEARCH THEORY}


Relevance Theory is a cognitive theory of human communication, which lays emphasis on the importance of optimal relevance. The allusion subtitle translation could be explained better by Relevance Theory through its principle of optimal relevance. Thus, this dissertation attempts to study allusion subtitle translation on the basis of Sperber and Wilson's RT, hoping to get a desirable method of allusion subtitle translation and provide a wide theoretical basis for the research of allusion subtitle translation.

According to Sperber and Wilson (1986), the notion of relevance was defined as a useful theoretical concept in a technical sense. Relevance is comparatively defined in terms of contextual effect and processing effort as "an assumption is relevance in a context if and only if it has some contextual effect in that context" (Sperber and Wilson, 1986, p.122). And its two extent conditions are as follows:

"An assumption is relevant in a context to the extent that its contextual effects in this context are large. An assumption is relevant in a context to the extent that the effort required to process it in this context is small." (Sperber and Wilson, 1986, p. 125). The definition shows that: when other things are equal, the relevance is depending on two factors, that is, the greater the cognitive effects, the greater the relevance; the smaller the processing effort, the greater the relevance.

According to Relevance Theory, the translation of allusions is difficult because on the one hand, the author uses allusions to deliver the rich and implicit implications, which need rich contextual effects in the corresponding translation; on the other hand, allusions are rooted in special culture, which requires higher cognitive environment and more efforts in understanding. Thus, we could redefine the dilemma in allusion translation based on Relevance Theory: in one way, the cultural elements in the allusions could be deleted and only the meaning is expressed in allusion translation to decrease the efforts needed by target readers, which will not succeed because it may not reach the Optimal Relevance since it has not produced enough contextual effects; in the other way, the cultural elements of the allusions could be reserved and translated directly so as to produce rich contextual effects, which will also not succeed because it may not reach the Optimal Relevance since it may cost the target viewers more efforts to understand it.

According to Relevance Theory, relevance is decided by context, and a sentence may have much different relevance in different contexts, which has important meaning to allusion translation: the success of translation is decided by the context of intention viewers. Thus, in allusion translation, the translator should first of all make sure of the differences between the context of target viewers and the required context for correctly understanding the allusion. The degree of resemblance between the original text and the translation is based on the above factor. Then, the translators must always keep Optimal Relevance in mind when choosing the specific translation strategies to make sure that the translation can produce enough contextual effects to the target viewers without the waste of excessive efforts. The translation will be successful when these two points are achieved.

\section{BRIEF INTROdUCTION OF THE SIMPSONS MoviE}

The Simpsons Movie, which was directed by David Silverman, is an American animated comedy film made in 2007 based on the animated cartoon sitcom The Simpsons. It is known as "the Encyclopedia of America", which is full of allusions which play a key role in adding the fun and humor of the movie, making the movie a bit difficult to understand, especially for a foreigner watching a translated version.

The film describes a recognizably American family in a fictional American town named Springfield. The Simpson family is a middle-class white family with a typical family structure of two adults, three kids, a cat and a dog. Using the environmental pollution as a clue, the movie describes the evil head of the Environmental Protection Agency who intends to destroy Springfield, in which a lake was polluted by Homer. At last, Homer succeeds to regain his dignity by stopping Cargill's scheme after being abandoned by his family and chased by the townspeople.

The film has reached a big commercial success and has won many awards. It grossed a combined total of $\$ 74,036,787$ in its opening weekend on 5,500 screens at 3,922 theaters, reaching the top of the box office for that weekend. (Net.1) The film's trailer, music and website also received great awards. It was also nominated for a series of awards before its release.

As have mentioned above, the film is full of allusions. Therefore, The Simpsons Movie is chosen to be an example in this dissertation. Berger (1997) thought that allusion could make it convenient to remind the reader of certain people and events, and enable people to see the current scene or situation based on this additional information. According to Berger, the viewer may not understand the allusions in a comedy from a different culture which leads to the loss of humor and a poor understanding of a movie. (Berger, 1997).

Lepphalme (1997) also believes that a cultural barrier can be a barrier in understanding an allusion, unless the receivers know well about the two cultures (Lepphalme, 1997). The audience of The Simpsons Movie is of various types, even in the original target culture. The translator should take the different age, gender and nationality of the audience into consideration when choosing the translation strategies. Being such a popular movie, its subtitle translation, especially allusion translation, is of great importance.

\section{Analysis on Allusion Translation from the Perspective of ReleVAnCe Theory}

People often use old allusions in new contexts to convey their new implications which make allusions implicit; 
Meanwhile, allusions are produced from cultural heritage familiar to people with the same historical and cultural backgrounds which add its cultural characters, including historical events, mythology, religion, literature works, fables and old legends.

Studies on allusion translation have focused on the fact that allusions are not always recognized by Target Language Viewers, who have a different cultural background than the source-text author and his/her original audience. Therefore, allusions should be translated with great care due to their implicity of meanings and distinct cultural property. It is always a dilemma for the translators to convey the implied information of the allusions while keep the original cultural property as much as possible (Wilss, 2001).

According to Relevance Theory, the translation of allusions is difficult because on the one hand, the author uses allusions to deliver the rich and implicit implications, which need rich contextual effects in the corresponding translation; on the other hand, allusions are rooted in special culture, which requires higher cognitive environment and more efforts in understanding. Thus, we could redefine the dilemma in allusion translation based on RT: in one way, the cultural elements in the allusions could be deleted and only the meaning is expressed in allusion translation to decrease the efforts needed by target readers, which will not succeed because it may not reach the Optimal Relevance since it has not produced enough contextual effects; in the other way, the cultural elements of the allusions could be reserved and translated directly so as to produce rich contextual effects, which will also not succeed because it may not reach the Optimal Relevance since it may cost the target viewers more efforts to understand it.

According to Relevance Theory, relevance is decided by context, and a sentence may have much different relevance in different contexts, which has important meaning to allusion translation: the success of translation is decided by the context of intention viewers. Thus, in allusion translation, the translator should first of all make sure of the differences between the context of target viewers and the required context for correctly understanding the allusion. The degree of resemblance between the original text and the translation is based on the above factor. Then, the translators must always keep Optimal Relevance in mind when choosing the specific translation strategies to make sure that the translation can produce enough contextual effects to the target viewers without the waste of excessive efforts. The translation will be successful when these two points are achieved.

\section{Non-VERBal Allusions in The Simpsons Movie}

There are two kinds of allusions in The Simpsons Movie: Verbal Allusions and Non-Verbal Allusions. (Net.2) Except verbal allusion, there are also many Non-Verbal Allusions which play a key role in the understanding and enjoying of the whole film. Here "non-verbal" refers to some texts or signs in certain scenes without sounds.

Whenever possible, you could find jokes or sight gags in signs, newspapers and elsewhere in the film with familiar background scenes. For example, there is a love scene in The Simpsons Movie which parodies many Disney films with Disney-style animals helping them undress; when in the Dare Contest, Bart is riding his skateboard naked, different passing objects are constantly covering his genitalia, a nod to similar techniques used in Austin Powers: International Man of Mystery; Hillary Clinton appears as Itchy's competitor, while an Orc from The Lord of the Rings appears in the mob scene. There are all together 14 NVA taken as examples in this chapter.

\section{A COMPARATIVE ANALYSIS OF NON-VERBAl Allusions OF THE Two CHINESE VERSIONS}

\section{A. The Non-verbal Allusion Appeared within Texts}

Examples 1 to 5 are Non-Verbal Allusions which appear in the written forms.

Example 1

When Itchy returns to his country, the other mice gather to elect him as their president. The words on one of the streamers is ITCHY/HILLARY'08.

Version 1: 依奇/希拉里 $\mathbf{0 8}$

Version 2: Omitted

Hillary Clinton appears as a U.S. presidential candidate. Hillary Clinton is a United States Senator for New York from 2001 to 2009. Being the wife of Bill Clinton, she is also the First Lady of the United States from 1993 to 2001. In January of 2007, Hillary expressed her wish to campaign for the president of the United States in 2008 through her personal website. Thus, the film is a spoof to Hillary. It is no doubt that the name Hillary is known to most of the TL viewers since she is a very famous politician of the United States. The translator should first let the target viewers know “Hillary” is “希拉里”, and the mice are electing for their president. Thus, the technique of replacing the name with TL form plus adding additional information should be adopted here in translating this allusion. For example, it could be translated as “依奇/希拉里 08 （竟选总统）”. However, both of the two versions fail to do so.

Example 2

LISA SIMPSON PRESENTS: AN IRRITATING TRUTH

Version 1: 丽莎·辛普森报告会：令人愤怒的真相

Version 2: Omitted

The name of Lisa's presentation at the town meeting is An Irritating Truth, which is a parody of the film name An 
Inconvenient Truth. The allusion used here to show the same purpose of avoiding pollution with the film An Inconvenient Truth which attempts to spread awareness of global warming to the whole world. When translating this allusion, the translator should think about two factors: first, whether the film An Inconvenient Truth is familiar to the TL viewers; second, whether it helps for comprehension of the present film plot to translate the allusion out. Since the film An Inconvenient Truth is probably not a well-known film to most of the target viewers, and the target viewers could enjoy the film to the same degree without the allusion being translated, the allusion could be translated into its TL form without further explanation just as version 1 does so as to achieve the best enjoyment. Therefore, the translator should omit the allusions sometimes due to the great cultural differences between the SL viewers and the TL viewers.

Example 3

In order to mourn the lately dead rock band Green Day, the church plays "American Idiot: Funeral Version". American Idiot, which is an album released in 2004 by Green Day, is a rock opera strongly criticizes the government and media.

Version 1: 美国白痴: 葬礼版

Version 2: Omitted

Due to the fact that American Idiot is an album produced by Green Day and the sarcastic feature of the album, the allusion should be translated by adding some additional information so that the target viewers could get enough contextual effect with the SL viewers who are familiar with this band and can easily get the laugh point. Thus, both of the two versions fail to achieve the optimal relevance. It could be translated as “美国白痴 (Green Play 的歌曲): 葬礼 版”.

Example 4

The name "Green Day" is shown on the streamer.

Version 1: Green Day 乐队

Version 2: Omitted

The man who is singing on the boat is Billie Joe Armstrong, the main singer of Green Day which is an American rock band formed in 1988. As the film shows, the band consists of three core members: Billie Joe Armstrong, Mike Dirnt and Tre Cool. Version 2 omits the name of the band totally which is not the best choice since the band appears one more time later. The target viewers will be confused about the plot if the allusion is not translated out here, which will cost more efforts of the target viewers. Version 1 translates the allusion by retaining the name and adding some additional information. But the target viewers will still not know that it is a real band of America, which may not raise the mocking effect as the film maker wants to show. Thus, the technique of adding footnote should be adopted here. For example, it could be translated as “Green Day（美国著名摇滚乐队）”.

Example 5

When in Eski-Moe, Homer plays a video game named Grand Theft Auto.

Version 1: 海象飞车

Version 2: Omitted

The video game Homer plays is a parody to the popular video game series Grand Theft Auto. The games are routinely criticized by its subject of violence. The video game in the movie is full of violence just as it is in real life. In the movie, Grand Theft Auto appears by taking almost half of the screen to attract the viewers' attention which makes the purpose of this allusion very clear. The allusion used here is an intention to show one aspect of the Homer's personality. As the picture has shown the violent action clearly enough, the target viewers can get the same contextual effects as the SL viewers do without knowing what the allusion is. Therefore, version 1 is a good translation by omitting the original allusion but translating its sense with the picture on the screen vividly described. Version 2 fails by losing the intention of the original film.

\section{B. The Techniques Used in Verbal Allusions without Texts}

Only five Non-Verbal Allusions appeared within texts are translated out, leaving the others omitted.

Example 6

Itchy kills Scratchy and makes up lies when he return to his country, but his people regard him as a hero and elect him as president. It is a parody of the famous political film Wag the Dog.

Example 7

In the dare contest, Bart rides his skateboard naked with different passing objects covering his genitalis constantly. This is a parody of the film International Man of Mystery which uses a same technique of expressing.

Example 8

In Homer and Marge's love scene in Alaska, many Disney-style animals appear to help them undress which is a parody to the Disney films.

Example 9

The dancing penguin appears in the game is also a reference to the penguin in the animated movie Happy Feet, who is out of home because of his dancing tendencies.

Example 10

The robot who is sent to dispose the bomb by the policemen of the Springfield commits suicide under great pressure. 
It is clearly a parody to the film Full Metal Jacket which contains a similar way of suicide.

Example 11

The immense shadow of the EPA dome which is delivered to Springfield and the reactions of the People inside the Springfield are quite like the film Independence Day, when the Alien Destroyers positioning themselves over Washington DC, New York City, and Los Angeles.

Example 12

Homer grabs on to a passing truck in order to get home after he comes out from Eski-Moe, a parody to actor Buster Keaton who was best known for his silent films.

Example 13

Trees can be found in every emotional or important scene throughout the film. When Lisa meets Colin for the first time, an apple tree is inserted behind them, a reference to the biblical story of Adam and Eve in the Garden of Eden.

Example 14

The crowds are celebrating their victory from being bombed at the end of the film. The same hand gesture of Carl is a parody of Lando Calrissiant's gestures in the film Star Wars Episode VI: Return of the Jedi.

The above eight Non-Verbal Allusions cannot be translated because of two reasons: the target viewers can easily recognize these allusions which are very popular to people all over the world, or the audience can get much information from the screen, such as the various expressions on their faces, the reaction they have made for the changes and so on. On the other hand, the viewers could not enjoy the pictures and music in a short time if too many words are inserted to explain the allusion. According to Relevance Theory, the Optimal Relevance will be achieved only with the most contextual effects and the least processing efforts. Thus, both of the two versions have not translated them out which are in accordance with the principle of relevance.

All the comparative analysis of Non-Verbal Allusions shows that adding further explanation is a quite common-used technique in translating all these kinds of allusions since it could make allusions more clear to the Target Language viewers which would help them with their understanding process and getting the most contextual effects with enough processing efforts. Omission is also used in translating the non-verbal allusions due to their unique features.

\section{MAIN FINDINGS}

The purpose of the dissertation is trying to find out the significant trend of the translator's choice of strategies in Non-Verbal Allusion subtitle translation. The examples of translated subtitles are taken from the movie screen produced by YYet and YDY subtitle groups and analyzed descriptively and explanatorily from a relevance-theoretical approach.

Based on Relevance Theory, some translation techniques below are concluded from the analysis of The Simpsons Movie, which could be also suitable for the translation of allusions in all movies of this kind. When translating Non-Verbal Allusion, four techniques could be used:

(1) Use its Target Language form when the allusion needs not to be translated, such as in example 2;

(2) Add further explanation to the allusion which could rise confusion to the Target Language viewers without further explanation, such as in example 1,3,4;

(3) Reduce the allusion to its sense by showing its meaning, such as in example 5;

(4) Omit it when it cannot be translated, such as in example 6-13.

It is sure that there are some limitations in this dissertation. Firstly, the present study is only a descriptive one with little empirical research. It does not test in a quantitative way how the Relevance Theory and its principle are going to guide the allusion subtitle translation. Secondly, the classification of the examples and their analysis are from the author's own understanding under the guidance of Relevance Theory, which might be incomplete and subjective to some extent. Thus, further exploration and research will be needed to improve the study. The author hopes that this dissertation can provide some enlightens to translation methods for allusion subtitles of all films from the Relevance Theory perspective, and hopes that more translators and researchers could pay attention to allusion subtitle translations so that foreign movies can be mostly enjoyed.

\section{REFERENCES}

[1] Gambier, Yves and Gottlieb, Henric. (2001). (Muti) media Translation: Concept, Practices, and Research. Shanghai: Shanghai Foreign Language Education Press.

[2] Leppihalme, Ritva. (1997). Culture Bumps: An Empirical Approach to the Translation of Allusions. Clevedon: Multilingual Matters.

[3] Peter, Berger. (1997). Redeeming Laughter: The Comic Dimension of Human Experience. New York: Walter de Gruyter.

[4] Sperber, Dan \& Wilson, Deirdre. (1986). Relevance: Communication and Cognition. Oxford: Basil Blackwell.

[5] Wilss Wolfram. (2001).The Science of Translation. Shanghai: Shanghai Foreign Language Education Press.

[6] Net. 1. The Simpsons Movie. http://www.en.wikipedia.org/wiki/The_Simpsons\#Film.html(accessed 2/10/2011).

[7] Net. 2. Allusions in The Simpsons Movie. http://www.en.wikipedia.org/wiki/The_Simpsons_Movie.html (accessed 12/1/2012). 
Juan Liu was born in Huhhot, China in 1981. She received master degree in linguistics from Inner Mongolia University, China in 2012. She is currently a lecturer in the Foreign languages department of Inner Mongolia University of Finance and Economics. Her research interests include translation and pedagogy.

Huijuan Jia was born in Huhhot, China in 1986. She received master degree in linguistics from Inner Mongolia University, China in 2012. She is currently a teacher in Foreign languages school in Haikou, China. Her research interests include translation. 